Plant Tissue Cult. \& Biotech. 22(2): 113-126, 2012 (December)

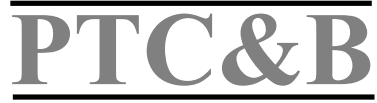

\title{
Effects of Hormonal and Basal Nutrient Medium on In vitro Regeneration of an Ornamental Plant - Muscari armeniacum Leichtlin. ex Baker
}

\author{
Mustafa Abul Kalam Azad* and Muhammad Nurul Amin \\ Department of Botany, University of Rajshahi, Rajshahi-6205, Bangladesh \\ Key words: Plant growth regulator, Micropropagation, Bulb-scale, Leaf-sheath, \\ Grape hyacinth
}

\begin{abstract}
In vitro propagation system has been developed for an important ornamental and medicinal plant, Muscari armeniacum Leichtil. ex Bak. A range of a cytokinin and auxin concentration has been investigated for axillary bulblet proliferation, and direct and indirect adventitious bulblet regeneration from the explants whole bulb, one fourth part of bulb, bulb-scale of ex vitro (field grown mature bulb), and only leaf-sheath explants of in vitro grown bulblet. Axillary bulblet regeneration occurred on MS containing 2.0 - $8.0 \mu \mathrm{M}$ BAP or Kn. Direct adventitious bulblets were induced successfully on MS basal medium supplemented with various concentrations of BAP or $\mathrm{Kn}(1.0-4.0 \mu \mathrm{M})$ in combi-nation of either NAA, IBA, or 2,4-D $(0.5-4.0 \mu \mathrm{M})$. The maximum frequency of adventitious bulblets regeneration occurred from both bulb-scale and leaf-sheath explants on MS with $4.0 \mu \mathrm{M}$ BAP and $2.0 \mu \mathrm{M}$ NAA, IBA, or 2,4-D. The highest frequency (95.5\%) of indirect adventitious bulblets was obtained from in vitro grown leaf-sheathderived callus on MS containing 4.0 $\mu \mathrm{M}$ BAP with $1.0 \mu \mathrm{M}$ 2,4-D whereas, highest number (80.2) and average length $(55.5 \mathrm{~cm})$ of bulblets were obtained on MS supplemented with $4.0 \mu \mathrm{M}$ BAP and $1.0 \mu \mathrm{M}$ NAA. In vitro grown bullets was rooted successfully on MS with $0.5-4.0 \mu \mathrm{M}$ of IBA, NAA, or IAA. The rooted bulblets were transferred to garden soil and successfully established under $e x$ vitro environment.
\end{abstract}

\section{Introduction}

Muscari armeniacum Leichtlin. ex Baker, generally known as Grape hyacinth, is an herbaceous plant of the genus Muscari native to Southern Europe, Northern Africa, Western Asia and Asia Minor. Grape hyacinths are small plants that

*Author for correspondence: <drmakazad@gmail.com> 
usually do not attain more than ten inches height with basal, simple leaves and short, flowering stem. The flowers are purple, blue (with a white fringe) or white, and bloom in spring. M. armeniacum is good for beds, borders, raised planters, rock gardens, mass plantings, or naturalized areas, and looks best when planted in groups, drift, or serpentine wide lines. Muscari flowers produce a sweet fragrance perfume which is similar to honey (Grey-Wilson et al. 1981) and are used in perfumery. In addition to being fantastic in appearance, Muscari flowers are also considered something of a delicacy and of important value in herbal medicine. In Greece, the bulbs of Muscari comosus are eaten in a picked form. As for their medicinal properties, these flowers can be used to create a short of sourtasting wine which is said to be high in vitamin $C$ and other antioxidants. The bulb may be crushed and mixed with a base to create poultice for red or irritated skin and they may also be boiled down into a tea that is an effective diuretic (http://www.botanical.com/botanical/mgmh/h/hyagra42.html).

M. armeniacum is propagated conventionally from bulb. A cool and moderate climate, and a freely draining, moist soil with $\mathrm{pH}$ approx. 7, without disease are for best propagating. M. armeniacum cultivation is not popular in Bangladesh due to the unpredictable climate condition and lack of proper cultivars. To induce variation, plants were regenerated using various tissue culture techniques. There are some reports on tissue culture propagation of Muscari plants (Nasircilar et al. 2011, Uranbey 2010a,b, Ozel et al. 2007, Nakano et al. 2005, Saniewski and Puchalski 1987, Peck and Cuming 1986, Suzuki and Nakano 2001). But so far known, there has been no report on in vitro propagation of this species in Bangladesh. Through tissue culture techniques it is possible to create variability and to produce huge number of plantlets. Considering these, the present investigation was undertaken to develop the tissue culture technique for rapid mass propagation of $M$. armeniacum from field grown mature plants and in vitro grown bulblets.

\section{Materials and Methods}

Mature bulbs of M. armeniacum were collected from Japan. After removing all bulky materials from the bulb they were washed with detergent containing water for $15 \mathrm{~min}$ and then rinsed thoroughly with running tap water for $20 \mathrm{~min}$. After this, bulbs were surface sterilized with $70 \%$ ethanol for $3 \mathrm{~min}$, they were moved to a laminar air flow cabinet and transferred to a sterilized conical flask. Subsequent surface disinfection was done with $0.1 \% \mathrm{HgCl}_{2}$ solution for $15 \mathrm{~min}$. To remove any trace of the sterilants, the bulbs were then washed with at least three changes of sterile distilled water. After that the bulbs were cut 
longitudinally in laminar air flow to obtain bulb scale $(5-7 \mathrm{~mm}$ in width and 8 $10 \mathrm{~mm}$ in length) explants and one fourth part of bulb segment consisting of $3-4$ scale segments attached to the basal plate. The entire meristematic tips measuring $5.0 \mathrm{~mm}$ were also isolated carefully. Bulb meristematic tip and one fourth cut bulb segment were cultured on MS containing 2.0 - 8.0 $\mu \mathrm{M}$ BAP or Kn singly for axillary bulblet proliferation. Leaf sheaths were prepared from sixweek-old aseptically grown bulblets, which were developed from meristem tip and bulb segment cultures. Bulb scale of field grown mature bulb and leaf sheath of in vitro grown bulblets were cultured on MS containing different concentrations $(1.0-4.0 \mu \mathrm{M})$ of BAP or $\mathrm{Kn}$ in combination with $0.5-4.0 \mu \mathrm{M}$ of NAA, IBA or 2,4-D for the induction of direct and indirect adventitious shoots. All explants were also cultured on B5 (Gamborg et al. 1968) and half strength of MS containing $4.0 \mu \mathrm{M}$ BAP with $2.0 \mu \mathrm{M}$ NAA to find out the effects of basal medium for direct or indirect adventitious bulblet regeneration.

To complete the regeneration of plantels, the microbulbs/bulblets with 2 - 4 $\mathrm{cm}$ long leaf were rooted on MS supplemented with different concentrations (0.5 - $4.0 \mu \mathrm{M}$ ) of IBA, NAA or IAA. The percentage of root formation, number of roots per bulblet, and length of the longest root were recorded after five weeks of the culture. The $\mathrm{pH}$ of both proliferation and rooting media was adjusted to $5.7 \pm$ 0.1 . The media were fortified with $3 \%$ sucrose $(\mathrm{w} / \mathrm{v})$ and gelled with $0.6 \%$ agar. The cultures (callus with 4 - 6 small shoots) were regularly sub-cultured on fresh medium at four weeks intervals. The cultures were grown at $25 \pm 1^{\circ} \mathrm{C}$ under illumination for $16 \mathrm{hrs}$ photoperiod with a light intensity of $50-60 \mu \mathrm{mol} / \mathrm{m}^{2} / \mathrm{s}$.

After one month of rooting, the rooted bulblets were removed from the culture medium, roots were washed thoroughly and carefully and then kept under tap water to remove all traces of agar. Subsequently, bulblets were transferred to plastic pots ( $6 \mathrm{~cm}$ diam.) containing garden soil, sand and compost $(1: 2: 1)$ for hardening under diffuse light (16 hrs photoperiod). The pots were covered with a transparent plastic tent to ensure high humidity during the acclimatization period of 20 days. They were maintained under culture room conditions. The potted plants were irrigated with tap water every four days for three weeks. The tent was removed after three weeks in order to acclimatize plants to laboratory room conditions. Acclimatized plants were then transferred to larger mud pots (12 cm diam.) and maintained in outdoor conditions.

The experiment had four replicates; each consisted of 20 culture flasks (200 $\mathrm{ml})$. Results were recorded at a regular interval of four weeks of culture and analyzed by analysis of variance using RBD method. Four subculture cycles were used, and after each subculture, percentage of axillary bulblet proliferation, direct and indirect adventitious bulblet formation, total number of bulblets, 
average length of bulblet, percentage of root formation, total number of roots, and average length of roots per culture were recorded. The effects of different treatments were compared to detect the significant differences among the treatment means using DMRT at 5\% probability level according to Gomez and Gomez (1984).

\section{Results and Discussion}

Bulb meristem tip and one fourth bulb segments from field grown mature plant of $M$. armeniacum were cultured on MS supplemented with BAP and $\mathrm{Kn}$ at different concentrations $(2.0,4.0,6.0$ and $8.0 \mu \mathrm{M})$ for proliferation of axillary bulblets. The proliferation efficiency of one fourth bulb segment from mature plant was significantly higher than that of meristem tip explant when evaluated after seven weeks of proliferation (Fig. 1a,b). As a supplement $4.0 \mu \mathrm{M}$ BAP showed the best performance of regeneration which induced bulblets in $100 \%$ cultured explants. The explant produced the highest number of 8.5 bulblets with $5.3 \mathrm{~cm}$ average length per culture on the same medium. On the other hand, though the meristem tip explants produced bulblets in $100 \%$ of the culture but these explants produced less number of 2.0 bulblets per culture with their average length of $6.5 \mathrm{~cm}$. When the explants were cultured on $\mathrm{Kn}$ based medium only $0.0-65.0 \%$ of the cultured explants showed response to shoot proliferation. In this treatment the highest number of bulblets per explant and average length of bulblets were 5.0 and $3.2 \mathrm{~cm}$ for one fourth bulb segments; and 1.0 and $3.5 \mathrm{~cm}$ for meristem tip explants, respectively. However, in general the cultured explants showed less proliferation in plant growth regulator (PGR) omitted MS (40.0\% for meristem tip and $20.0 \%$ for one fourth bulb segment) than those cultured in PGR supplemented MS (Table 1).

The concentrations and combinations of PGR gave a marked effect on axillary bulblet regeneration, direct and indirect adventitious bulblet proliferation from different explants of $M$. armeniacum. Generally, percentage of shoot formation, number of total bulblets, and average length of bulblet per explant increased up to a certain concentration depending on the kind of PGR and the types of explants. A higher concentration of cytokinin produces profuse callusing and reduces shoot bud induction (Tiwari et al. 2001).

The axillary bulblet formation started with single bulblet from the basal plate following the additional bulblets subsequently after two weeks of culture. All the axillary bulblets increased in their size after four - six weeks of culture. Among the two types of explants one fourth bulb explants showed good response for axillary bulblet regeneration than the whole bulb cultured explants. This study 
clearly demonstrates a significant influence of $4.0 \mu \mathrm{M}$ BAP on axillary bulblet regeneration of $M$. armeniacum using one fourth bulb explants on MS. It was noted down that at high $(>4.0 \mu \mathrm{M})$ and low $(<4.0 \mu \mathrm{M})$ concentration of BAP or Kn

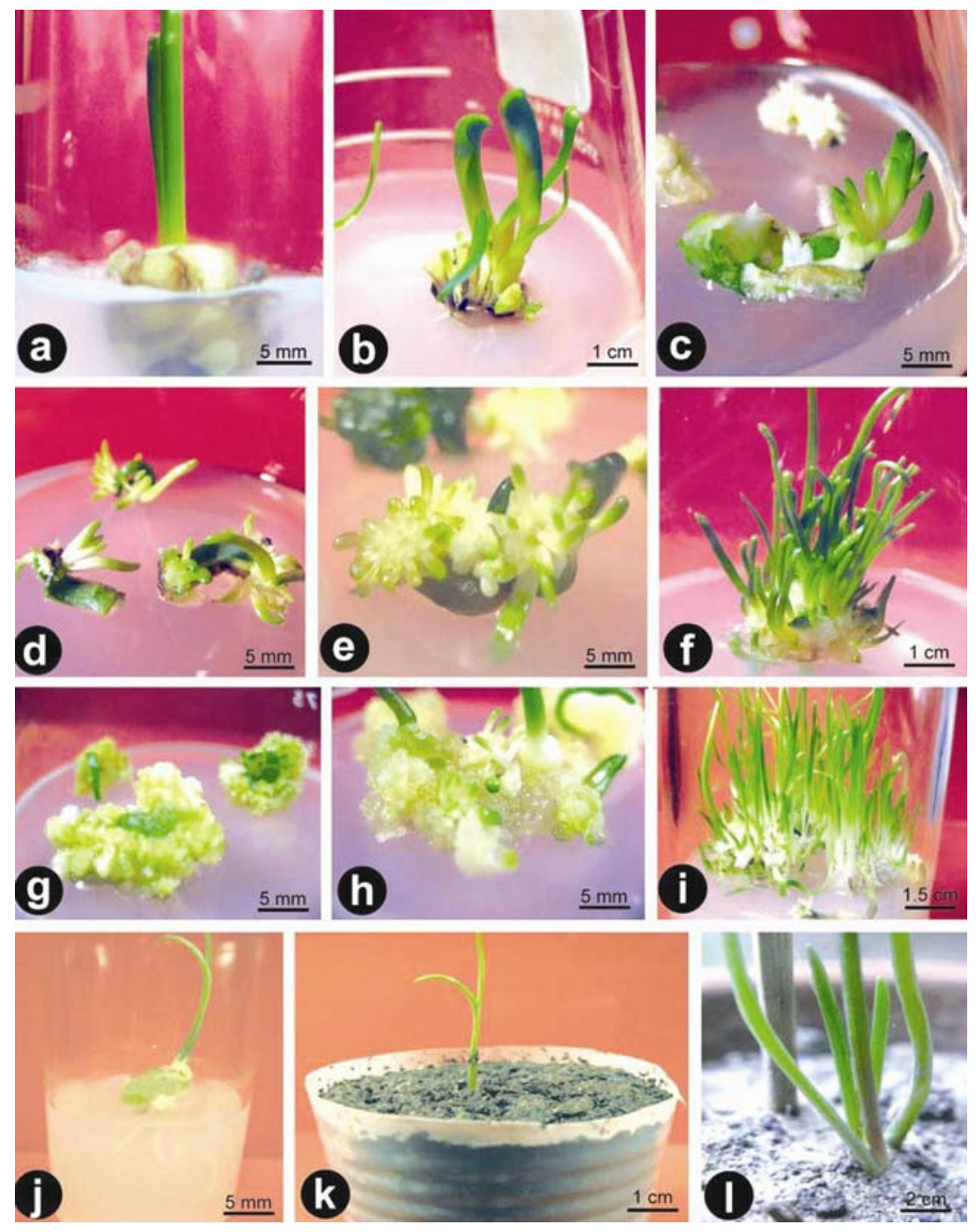

Fig. 1. Regeneration of plantlets from ex vitro and in vitro grown explants. Development of axillary bulblet from meristem tip (a), one fourth bulb segment (b). Development of direct adventitious bulblets from ex vitro grown bulb scale (c). Development of direct adventitious bulblets from in vitro grown leaf-sheath explants after four weeks (d), six weeks (e) and ten weeks of culture incubation. Development of indirect adventitious bulblets from ex vitro grown leaf-sheath derived callus after five weeks (g), seven weeks and ten weeks of culture incubation (i). Rooting of the in vitro proliferated bulblet (j). Regenerated bulblet on soil after three weeks (k) and ten weeks (l) of transfer under ex vitro condition. 
showed dramatic decrease in bulblet induction. Moreover, addition of auxins in cytokinins also reduce the axillary bulblet proliferation (data not shown), which is in agreement to Saniewski and Puchalski (1987) who found that the initiation of bulblets was strongly inhibited by auxins in M. comosum and M. botryoites. It was also noted that MS without PGR was not more effective for stimulating bulblet regeneration and induced only 2.1 axillary bulblets per one fourth bulb segment explant. This was supported by the results found in M. marocarpum (Ozel et al. 2007).

Table 1. Effect of cytokinins and their concentrations on axillary shoot proliferation of

M. armeniacum.

\begin{tabular}{|c|c|c|c|c|c|}
\hline PGR & $\begin{array}{l}\text { PGR } \\
\text { conc } \\
(\mu \mathrm{M})\end{array}$ & Explant & $\begin{array}{c}\text { Bulblet } \\
\text { formation } \\
(\%)\end{array}$ & $\begin{array}{c}\text { Mean No. } \\
\text { of } \\
\text { bulblets/ } \\
\text { culture }\end{array}$ & $\begin{array}{c}\text { Average } \\
\text { length of } \\
\text { bulblets }(\mathrm{cm})\end{array}$ \\
\hline${ }^{*} \mathrm{HO}$ & - & Meristem tip & 40.01 & $1.2 \mathrm{e}$ & $2.0 \mathrm{e}$ \\
\hline $\mathrm{HO}$ & - & $1 / 4$ bulb segment & $20.0 n$ & $2.1 \mathrm{e}$ & $1.5 \mathrm{e}$ \\
\hline \multirow[t]{8}{*}{ BAP } & 2.0 & Meristem tip & $80.0 \mathrm{~d}$ & $1.3 \mathrm{e}$ & $5.2 b$ \\
\hline & 4.0 & & $100.0 \mathrm{a}$ & $2.2 \mathrm{e}$ & $6.5 \mathrm{a}$ \\
\hline & 6.0 & & $75.0 \mathrm{e}$ & $1.1 \mathrm{e}$ & $4.1 \mathrm{c}$ \\
\hline & 8.0 & & $60.0 \mathrm{~h}$ & $1.0 \mathrm{e}$ & $2.5 \mathrm{~d}$ \\
\hline & 2.0 & $1 / 4$ bulb segment & $85.0 \mathrm{c}$ & $5.1 \mathrm{c}$ & $4.5 \mathrm{c}$ \\
\hline & 4.0 & & $100.0 \mathrm{a}$ & $8.5 \mathrm{a}$ & $5.3 \mathrm{~b}$ \\
\hline & 6.0 & & $95.0 \mathrm{~b}$ & $6.2 b$ & $4.2 \mathrm{c}$ \\
\hline & 8.0 & & $70.0 \mathrm{f}$ & $4.1 \mathrm{~d}$ & $2.1 \mathrm{e}$ \\
\hline \multirow[t]{8}{*}{ Kn } & 2.0 & Meristem tip & $50.0 \mathrm{j}$ & $1.2 \mathrm{e}$ & $3.2 \mathrm{~d}$ \\
\hline & 4.0 & & $60.0 \mathrm{~h}$ & $1.3 \mathrm{e}$ & $3.5 \mathrm{~d}$ \\
\hline & 6.0 & & $45.0 \mathrm{k}$ & $1.1 \mathrm{e}$ & $1.7 \mathrm{e}$ \\
\hline & 8.0 & & 0.0 & 0.0 & 0.0 \\
\hline & 2.0 & one fourth bulb segment & $65.0 \mathrm{~g}$ & 3.1e & 2.6e \\
\hline & 4.0 & & $70.0 \mathrm{f}$ & $5.2 \mathrm{c}$ & $3.2 \mathrm{~d}$ \\
\hline & 6.0 & & $55.0 \mathrm{i}$ & $2.2 \mathrm{e}$ & $1.3 \mathrm{e}$ \\
\hline & 8.0 & & $30.0 \mathrm{~m}$ & $2.1 \mathrm{e}$ & $1.2 \mathrm{e}$ \\
\hline
\end{tabular}

Each mean is based on four replicates. Values with different letters are significantly different from each other at $5 \%$ level according to DMRT. *Hormone free.

The effects of different concentrations and combinations of cytokinins and auxins on multiple adventitious bulblet induction were studied using bulb-scale explants from field grown plants and leaf-sheath explants from in vitro grown bulblets. These explants were also cultured on MS supplemented with different 
concentrations $(1.0,2.0,3.0$ and $4.0 \mu \mathrm{M})$ of BAP or $\mathrm{Kn}$ in combinations with NAA, IBA and 2,4-D for regenerating direct adventitious bulblets. The results of the best concentration of BAP or Kn $(4.0 \mu \mathrm{M})$ with $2.0 \mu \mathrm{M}$ NAA, IBA or 2,4-D are shown only (Table 2). After four weeks of culture, the bulb-scale and leafsheath explants showed development of direct adventitious shoot buds from the cut ends without the formation of callus (Fig. 1c,d). Among the different cytokinin-auxin combinations tested, BAP-2,4-D formulation showed the better performance for direct adventitious bulblet formation from the bulb-scale and leaf-sheath explants than the other combinations (Table 2). Among the all PGR combinations used in this experiment, the bulb-scale and leaf-sheath explants produced direct adventitious bulblets in all most all combinations. In this study the low concentration of cytokinins and high concentrations of auxins failed to produce any adventitious bulblet, but they produced large amount of calli. Among the various combinations the highest regeneration response achieved with both bulb-scale and leaf-sheath explants was recorded in the medium containing $4.0 \mu \mathrm{M}$ BAP plus $2.0 \mu \mathrm{M}$ 2,4-D. After six weeks of incubation the maximum frequency of direct bulblet differentiation was $100.0 \%$ for leaf-sheath and $95.5 \%$ for bulb-scale explants. Besides, another combination of $4.0 \mu \mathrm{M}$ BAP plus $2.0 \mu \mathrm{M}$ NAA or IBA also produced satisfactory direct adventitious shoot bud formation from both the explants (Table 2).

The maximum mean number of bulblets per culture was 50.5 for leaf-sheath and 30.3 for bulb-scale explants, which were recorded on MS with $4.0 \mu \mathrm{M}$ BAP plus $2.0 \mu \mathrm{M}$ NAA and $4.0 \mu \mathrm{M}$ BAP plus $2.0 \mu \mathrm{M}$ 2,4-D, respectively (Fig. 1f, c). On the other hand highest average length of the elongated bullets 47.4 and $42.7 \mathrm{~mm}$ were found from leaf sheath and bulb scale explants on the medium containing $4.0 \mu \mathrm{M}$ BAP plus $2.0 \mu \mathrm{M}$ IBA, respectively. Among all the treatments in vitro grown leaf-sheath explant showed the better performance for all parameters than ex vitro grown bulb-scale explant (Table 2 ).

Leaf-sheath explant of M. armeniacum is considered to be the best explant for direct adventitious bulblet regeneration, which is in agreement with the findings of Nasircilar et al. (2011). Furthermore, leaf-sheath explant has the advantages of easy manipulation and large number of explants can be obtained from leafderived callus (Suzuki and Nakano 2001). Among various concentrations and combinations of BAP and 2,4-D, leaf-derived callus of $M$. armeniacum showed the best result on $4.0 \mu \mathrm{M}$ BAP and $2.0 \mu \mathrm{M}$ 2,4-D. Suzuki and Nakano (2001) reported that high concentration of 2,4-D $(4.5 \mu \mathrm{M})$ with low concentration of BA $(0.44-4.4$ $\mu \mathrm{M})$ produced indirect adventitious bulblet from leaf-derived callus of $M$. armeniacum. It was also reported that high concentration of cytokinin and low concentration of auxin developed somatic embryo, subsequently adventitious 
shoot from leaf of petiole derived callus of Spathiphyllum (Zhao et al. 2012). The present study is in agreement with this study.

Table 2. Effect of different growth regulators on direct bulblet regeneration from ex vitro grown bulb-scale and in vitro grown leaf-sheath explants of $M$. armeniacum.

\begin{tabular}{lllccc}
\hline PGR & $\begin{array}{l}\text { PGR } \\
\text { conc. } \\
(\mu \mathrm{M})\end{array}$ & Explant & $\begin{array}{c}\text { Bulblet } \\
\text { formation } \\
(\%)\end{array}$ & $\begin{array}{c}\text { Mean No. of } \\
\text { bulblets/ } \\
\text { culture }\end{array}$ & $\begin{array}{c}\text { Average } \\
\text { length of } \\
\text { bulblets }(\mathrm{mm})\end{array}$ \\
\hline BAP + NAA & $4.0+2.0$ & Bulb scale & $70.5 \mathrm{~d}$ & $18.7 \mathrm{e}$ & $40.3 \mathrm{~d}$ \\
$\mathrm{BAP}+$ IBA & $4.0+2.0$ & Bulb scale & $65.5 \mathrm{e}$ & $15.4 \mathrm{f}$ & $44.7 \mathrm{~b}$ \\
& & Leaf sheath & $80.5 \mathrm{c}$ & $40.4 \mathrm{c}$ & $47.7 \mathrm{c}$ \\
$\mathrm{BAP}+2,4-\mathrm{D}$ & $4.0+2.0$ & Bulb scale & $75.0 \mathrm{~d}$ & $30.3 \mathrm{~d}$ & $22.4 \mathrm{~h}$ \\
& & Leaf sheath & $100.0 \mathrm{a}$ & $44.2 \mathrm{~b}$ & $30.1 \mathrm{~g}$ \\
$\mathrm{Kn}+\mathrm{NAA}$ & $4.0+2.0$ & Bulb scale & $45.0 \mathrm{~h}$ & $14.2 \mathrm{f}$ & $35.1 \mathrm{f}$ \\
$\mathrm{Kn}+\mathrm{IBA}$ & \multirow{2}{*}{$4.0+2.0$} & Leaf sheath & $55.0 \mathrm{~g}$ & $30.7 \mathrm{~d}$ & $39.3 \mathrm{~d}$ \\
& & Bulb scale & $35.5 \mathrm{i}$ & $12.5 \mathrm{f}$ & $37.2 \mathrm{e}$ \\
$\mathrm{Kn}+2,4 \mathrm{D}$ & $4.0+2.0$ & Bulb scale & $40.5 \mathrm{~h}$ & $26.3 \mathrm{~d}$ & $42.5 \mathrm{c}$ \\
& & Leaf sheath & $60.5 \mathrm{f}$ & $30.2 \mathrm{~d}$ & $16.4 \mathrm{j}$ \\
\hline
\end{tabular}

Each mean is based on four replicates. Values with different letters are significantly different from each other at 5\% level according to DMRT.

Adventitious bulblet regeneration from bulb-scale explant has also been achieved in a wide range of a bulbous species using a BAP plus NAA or 2,4-D combination (Uranbey 2010a, Tang et al. 2010). Superior effect of the BAP plus NAA combination on adventitious shoot bud proliferation from bulb-scale has also been reported by Mirici et al. (2005) for Sternbergia fischeriana. In the present study, authors found that BAP with 2,4-D, NAA or IBA successfully produced direct adventitious bullets from bulb-scale with the high percentage 95.4, 90.0 and 85.7, respectively, although bulb scale explant showed less bulblets formation and proliferation rates than leaf sheath explant. Similar results were reported in Muscari aucheri (Uranbey 2010b). Statistical analysis proved that the in vitro grown leaf-sheath explant was more effective for bulblet regeneration as well as production of highest number and length of bulblet than ex vitro grown bulb-scale explant.

In the present study, the cultured explants of leaf-sheath segments responded to callus formation and subsequently to bulblet regeneration under the influence of growth regulators. Among the different concentrations and 
combinations of the growth regulators in MS 4.0 $\mu \mathrm{M}$ BAP plus $4.0 \mu \mathrm{M}$ NAA or 2,4-D was best for callusing. This callus was used for bulblet regeneration by transferring them on MS supplemented with various concentrations and combinations of BAP and $\mathrm{Kn}$ and NAA, IBA and 2,4-D. Among these combinations and concentrations the cultured callus showed best bulblet formation on the medium containing $4.0 \mu \mathrm{M}$ BAP with $1.0 \mu \mathrm{M} 2,4-\mathrm{D}$. This combination showed maximum frequency of $90.5 \%$ for bulblet regeneration; whereas, the highest number (80.2) of bulblets and average length $(58.3 \mathrm{~mm})$ of bulblets were recorded on MS containing $4.0 \mu \mathrm{M}$ BAP with $1.0 \mu \mathrm{M}$ NAA and 4.0 $\mu \mathrm{M}$ BAP with $1.0 \mu \mathrm{M}$ IBA, respectively (Fig. 1i). Statistical analysis revealed that the above mentioned combinations and concentrations are significantly different from other formulations though they showed satisfactory bulblets regeneration on the same medium.

Significant differences in the percentage of callus formation were observed among the various concentrations and combinations of cytokinins and auxins $(p<0.01)$. Plant growth regulators were significant regarding the percentage of explants forming callus on callus formation media (data not shown). The highest percentages of callus formation (100\%) were obtained from leaf-sheath explant cultured on MS containing BAP and $4.0 \mu \mathrm{M}$ 2,4-D or NAA. Tang et al. (2010) reported that BAP and 2,4-D was the suitable for callus induction from leaf explant of Lilium leucanthum. Suzuki and Nakano (2001) also reported that leaf explant of $M$. armeniacum was suitable for callus induction. Calli were subcultured to MS with $4.0 \mu \mathrm{M}$ BAP or Kn and $0.5-2.0 \mu \mathrm{M}$ NAA, IBA or 2,4-D at four-week intervals. During subculture, some callus differentiated spontaneously into bulblets. In all treatments where callus differentiated into bulblets, and maximum 80.2 well-formed bulblets were obtained from $1.5 \mathrm{~g}$ of fresh callus on medium with $4.0 \mu \mathrm{M}$ BAP and 1.0 $\mu \mathrm{M}$ NAA. Suzuki and Nakano (2001) noted that high concentration of BAP and low concentration of NAA was more efficient for bulblet induction from leaf-derived callus.

Among the three types of basal media tested here MS nutrient medium showed the better response for all parameters which was followed by half strength of MS and B5 basal medium. In this study, highest 100\% bulblet formation were obtained from leaf-sheath explant, whereas the maximum number (78) and the longest $(55 \mathrm{~mm}$ ) bulblets were found in callus culture on MS basal medium. The lowest percentage of bulblet formation, number of bulblets and bulblet length were recorded on B5 basal medium (Fig. 2).

Analysis of variance revealed that significant differences among different explants, plant growth regulators, and their concentrations, which influenced the differences on percentage of adventitious bulblet formation, mean number of 
bulblets, and average length of bulblets per explant (data not shown). The highest mean value indicates that in respect of total number of bulblets per culture and average length of bulblets, all explants and plant growth regulator combinations were statistically significant at $5 \%$ level according to DMRT. BAP $(4.0 \mu \mathrm{M})$ plus $2,4-\mathrm{D}(2.0 \mu \mathrm{M})$ combination was significantly different from $4.0 \mu \mathrm{M}$ BAP plus either of $2.0 \mu \mathrm{M}$ NAA, or IBA; or $4.0 \mu \mathrm{M}$ Kn plus either of NAA, IBA or 2,4-D combinations for all the parameters. The regeneration efficiency significantly depended on explant type, PGR and the types of basal nutrient medium. Among the three nutrient medium MS basal medium was significantly different than other two basal media.

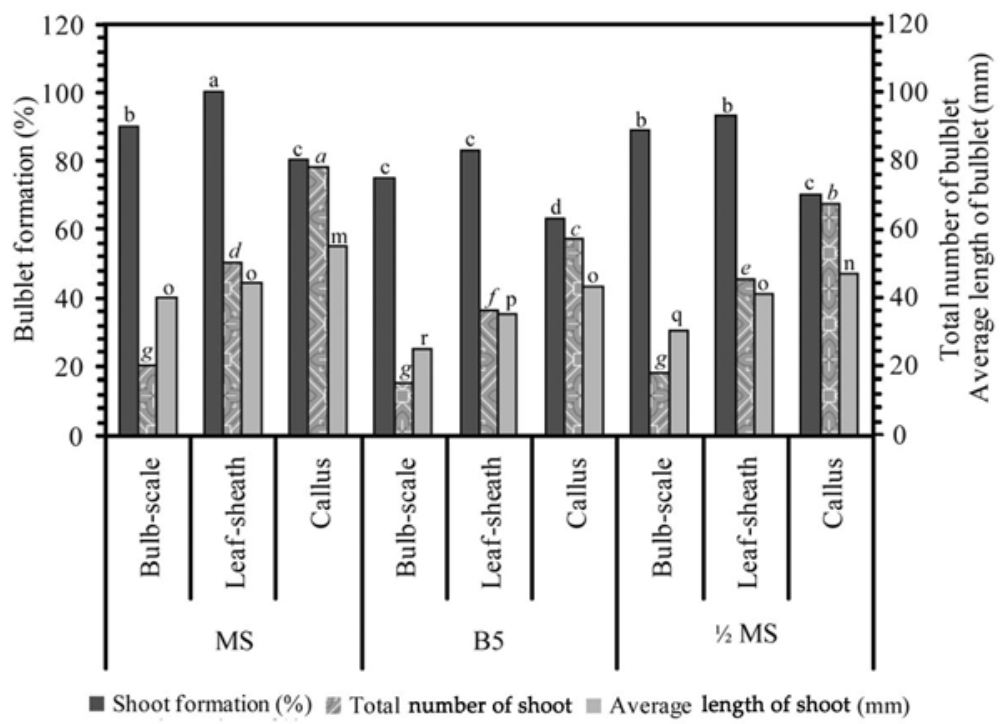

Fig. 2. Effect of basal media on bulblet regeneration from different types of explants.

Gamborg et al. (1976) reported that for tissue culture method various components are needed but the basal nutrient medium is one of the most important factors influencing the success of culturing plant material in in vitro conditions. The results of present study showed that three types of basal media (MS, B5 and half strength of MS) developed bulblet regeneration. High frequency of bulblet regeneration was obtained on MS basal salts and vitamins which were followed by B5 and half strength of MS. Uranbey (2010b) reported that Nitsch (1969) medium was suitable for shoot and bulblet generation. In his report he noted that highest number of bulblet regeneration per explant was 27.2, whereas in present study authors reported that maximum highest number 78 of bulblets were obtained on MS. Earlier studies regarding shoot and bulblet multiplication 
in geophytes indicated that the addition of growth regulators to the basal media promoted bulblet regeneration from many geophytes (Wawrosch et al. 2001, Mirici et al. 2005).

Table 3. Effect of different growth regulators on indirect bulblet regeneration from leaf-sheath derived callus of M. armeniacum.

\begin{tabular}{llccc}
\hline PGR & $\begin{array}{l}\text { PGR conc. } \\
(\mu \mathrm{M})\end{array}$ & $\begin{array}{c}\text { Bulblet } \\
\text { formation }(\%)\end{array}$ & $\begin{array}{c}\text { Mean No. of } \\
\text { bulblets/culture }\end{array}$ & $\begin{array}{c}\text { Average length } \\
\text { of bulblets }(\mathrm{mm})\end{array}$ \\
\hline BAP + NAA & $4.0+0.5$ & $60.0 \mathrm{e}$ & $60.4 \mathrm{c}$ & $45.8 \mathrm{c}$ \\
& $4.0+1.0$ & $80.5 \mathrm{~b}$ & $80.2 \mathrm{a}$ & $55.5 \mathrm{a}$ \\
& $4.0+2.0$ & $35.0 \mathrm{i}$ & $20.2 \mathrm{~h}$ & $20.1 \mathrm{f}$ \\
BAP + IBA & $4.0+0.5$ & $55.0 \mathrm{f}$ & $50.0 \mathrm{~d}$ & $50.5 \mathrm{~b}$ \\
& $4.0+1.0$ & $75.0 \mathrm{c}$ & $70.9 \mathrm{~b}$ & $58.3 \mathrm{a}$ \\
& $4.0+2.0$ & $30.0 \mathrm{k}$ & $17.6 \mathrm{~h}$ & $25.4 \mathrm{e}$ \\
BA+2,4-D & $4.0+0.5$ & $70.0 \mathrm{c}$ & $35.4 \mathrm{f}$ & $21.2 \mathrm{f}$ \\
& $4.0+1.0$ & $90.5 \mathrm{a}$ & $55.4 \mathrm{~d}$ & $35.3 \mathrm{~d}$ \\
& $4.0+2.0$ & $40.5 \mathrm{~h}$ & $13.1 \mathrm{~h}$ & $13.4 \mathrm{f}$ \\
Kn+ NAA & $4.0+0.5$ & $50.0 \mathrm{~g}$ & $25.3 \mathrm{~g}$ & $33.1 \mathrm{~d}$ \\
& $4.0+1.0$ & $65.0 \mathrm{~d}$ & $50.6 \mathrm{~d}$ & $50.4 \mathrm{~b}$ \\
& $4.0+2.0$ & $15.5 \mathrm{~m}$ & $11.2 \mathrm{~h}$ & $15.3 \mathrm{f}$ \\
Kn+ IBA & $4.0+0.5$ & $40.0 \mathrm{~h}$ & $20.1 \mathrm{~h}$ & $38.4 \mathrm{~d}$ \\
& $4.0+1.0$ & $55.0 \mathrm{f}$ & $40.4 \mathrm{e}$ & $51.3 \mathrm{~b}$ \\
& $4.0+2.0$ & $20.0 \mathrm{~m}$ & $9.1 \mathrm{~h}$ & $19.1 \mathrm{f}$ \\
Kn+2,4D & $4.0+0.5$ & $45.5 \mathrm{~g}$ & $14.3 \mathrm{~h}$ & $14.2 \mathrm{f}$ \\
& $4.0+1.0$ & $70.5 \mathrm{c}$ & $40.6 \mathrm{e}$ & $25.3 \mathrm{e}$ \\
& $4.0+2.0$ & 25.01 & $5.7 \mathrm{~h}$ & $10.1 \mathrm{f}$ \\
\hline
\end{tabular}

Each mean is based on four replicates. Values with different letters are significantly different from each other at $5 \%$ level according to DMRT.

IBA was comparatively more effective than NAA and IAA for rooting. Among the different concentrations, the maximal $95.5 \%$ of the culture produced roots when the bulblets were cultured on the medium containing $2.0 \mu \mathrm{M}$ IBA (Fig. 1j). Media containing NAA and IAA also resulted in root formation whereas the rooting response was not as good as in the IBA-containing media. Highest number of 8.2 roots per bulblet and the highest length of the longest root (55.3 $\mathrm{mm}$ ) were recorded on $2.0 \mu \mathrm{M}$ IBA-containing medium. These results indicated that percentage of root formation and number of roots per bulblet was highly influenced by concentrations and type of auxin. Poor rooting was obtained with IAA at all the concentrations compared to IBA and NAA, though $4.0 \mu \mathrm{M}$ 
IBA gave lower results on root-formation frequency and number of roots per bulblet (data not shown). Rooting responses of bulblets were highly significant ( $\mathrm{p}$ 0.01), suggesting that they were largely influenced by types of PGR and their concentrations. The significant differences among the means of different types of PGRs were evaluated with the help of DMRT. The highest values for all the characters were obtained with IBA, followed by NAA and IAA, and the differences among them were significant (Fig. 3).

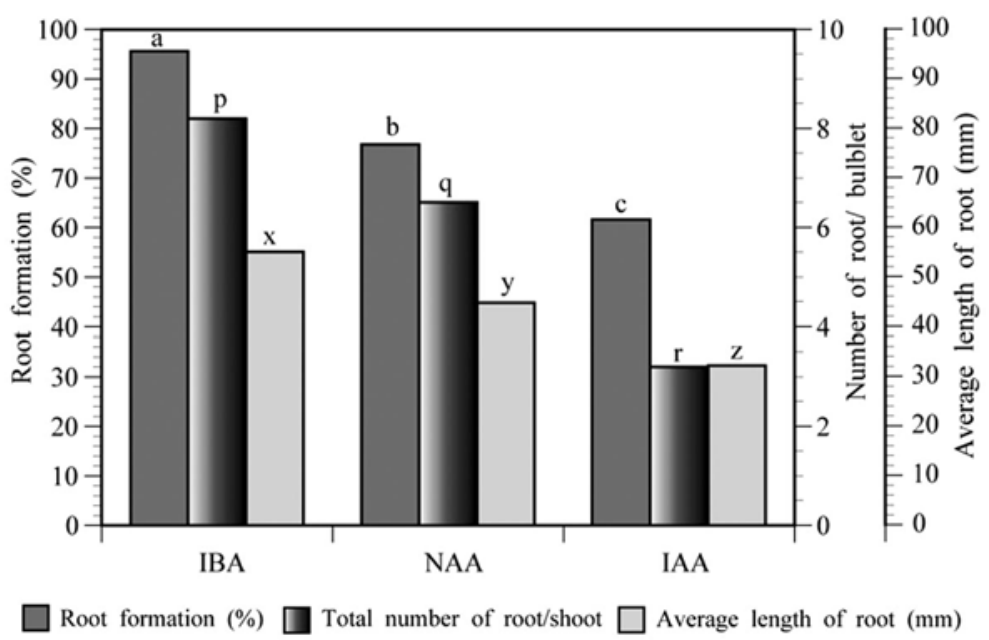

Fig. 3. Effect of auxins on root induction from in vitro grown micro-bulblet.

In this study, the rooting response of excised bulblet on MS containing IBA was better than that in either NAA or IAA. Being of stable nature, IBA is the preferred auxin for adventitious root initiation in many species e.g., M. aucheri (Uranbey 2010b), M. azureum (Uranbey 2010a) etc. In addition, success of auxinfree basal medium for efficient root induction is also reported by Kumar et al. (2011). In the present investigation, it is reported that auxin is needed for the induction of roots in M. aucheri (Uranbey 2010b). In the case of M. armeniacum, IBA is the best auxin for rooting from bulblet.

Normal growth of the potted plants was observed after $15-20$ days of transfer (Fig. 1k). After two months, they were moved to another larger pot $(12 \times$ $18 \mathrm{~cm}$ ) containing the same soil. The in vitro grown plantlets were gradually acclimatized and successfully established under ex vitro condition, with a survival rate of $95 \%$ (Fig. 11), where they showed no morphological variation with mother plants.

In conclusion, we have established a simple and efficient protocol for regeneration of plantlets through axillary, and adventitious (direct and indirect) bulb formation from ex vitro grown bulb and bulb-scale, and in vitro grown leaf- 
sheath explants of $M$. armeniacum. This protocol has the potential to perpetuate the germplasm of Muscari. The protocol was optimized by manipulations of different explants from axenic plants and explants placement on the shoot induction medium containing various concentrations and combination of BAP with NAA, IBA or 2,4-D. Protocols described here provide a rapid plant regeneration system which could be used for the large scale micropropagation of Muscari. Further studies could concentrate on rapid multiplication and germplasm conversation of $M$. armeniacum with bioreactor technology, and optimizing transformation conditions for genetic improvement.

\section{References}

Gamborg OL, Miller RA and Ojima O (1968) Nutrient requirements of suspension cultures of soybean root cell. Exp. Cell Res. 50: 151-158.

Gamborg OL, Murashige T, Thorpe TA and Vasil IK (1976) Plant tissue culture media. In vitro. 12: 473-478.

Gomez KA and Gomez AA (1984) Statistical procedures for agricultural research. (2 $2^{\text {nd }}$ ed). Wiley, New York. p. 680.

Grey-Wilson C, Mathew B and Blamey M (1981) Bulbs: The bulbous plants of Europe and their allies, London: Collins, ISBN 978-0-00-219211-8, p. 115.

http://www.botanical.com/botanical/mgmh/h/hyagra42.html.

Kumar M, Singh S and Singh S (2011) In vitro morphogenesis of a medicinal plant - Aloe vera L. Asian J. Plant Sci. Res. 1: 31-40.

Mirici S, Parmaksız I, Ozcan S, Sancak C, Uranbey S, Sarıhan EO, Gümüşcü A, Gürbüz B and Arslan N (2005) Efficent in vitro bulblet production from immature embryos of endangered Sternbergia fischeriana. Plant Cell Tiss. Org. Cult. 80: 239-246.

Nakano M, Tanaka S, Kagami S and Saito H (2005) Plantlet regeneration from protoplast of Muscari armeniacum Leichtl. ex Bak. Plant Biotechnol. 22: 249-251.

Nasircilar A G, Mirici S, Karaguzel O, Eren O and Baktir I (2011) In vitro propagation of endemic and endangered Muscari mirum from different explants types. Turk J. Bot. 35: 37-43.

Nitsch JP (1969) Experimental androgenesis in Nicotiana. Phytomorphology 19: 38-404.

Ozel CA, Khawar KM and Unal F (2007) In vitro axillary bulblet regeneration of Turkish Yellow Grape Hyacinth (Muscari macrocarpum Sweet) from twin scale explants. Res. J. Agril. Biological Sci. 3: 924-929.

Peck DE and Cuming BG (1986) Beneficial effects of activated charcoal on bulblet production in cultures of Muscari armeniacum. Plant Cell Tiss. and Org. Cult. 6: 9-14

Saniewski M and Puchalski J (1987) The effect of methyl jasmonate and abscisic acid on differentiation on benzyladenine induced bulblets in Muscari bulbs. Biologia Plantarum (PRAHA). 29: 63-65. 
Suzuki S and Nakano M (2001) Organnogenesis and somatic embryogenesis from callus cultures in Muscari armeniacum Leichtl. ex. Bak. In Vitro Cell. Dev. Biol. Plant. 37: 382387.

Tang YP, Liu XQ, Wahiti Gituru R and Chen LQ (2010) Callus induction and plant regeneration from in vitro cultured leaves, petioles and scales of Lilium leucanthum (Baker) Baker. Biotechnol. \& Biotechnol. Eq. 24: 2071-2076.

Tiwari SB, Wang XJ, Hagen G and Guilfoyle TJ (2001) Aux/IAA proteins are active repressors and their stability and activity are modulated by auxin. Plant Cell 13: 28092822.

Uranbey S (2010a) In vitro bulblet regeneration from immature embryos of Muscari azureum. African J. Biotechnol. 9: 5121-5125.

Uranbey S (2010b) Stimulating Effects of different basal media and cytokinin types on regeneration of endemic and endangered Muscari aucheri. Arch. Biol. Sci., Belgrade. 62: 663-667.

Wawrosch C, Malia PR and Kopp B (2001) Clonal propagation of Lilium nepalense D. Don, a threatened medicinal plant of Nepal. Plant Cell Rep. 20: 285-288.

Zhao J, Cui J, Liu J, Liao F, Henny RJ and Chen J (2012) Direct somatic embryogenesis from leaf and petiole explants of Spathiphyllum 'Supreme' and analysis of regenerants using flow cytometry. Plant Cell Tiss. Org. Cult. 110: 239-249. 